\title{
Study on the Design of Electronic Commerce Website
}

\author{
An Wang ${ }^{1, a}$, Rongfei Chu ${ }^{2, b}$ \\ ${ }^{1}$ Education School, Jiangxi Science \& Technology Normal University, Nanchang, China \\ 2 Jiangxi Science \& Technology Normal University, Nanchang, China

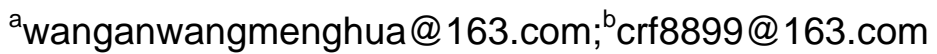

Keywords: electronic commerce; website design; design principle

\begin{abstract}
E-commerce, as an imporpant business operation means in the modern society, has spread to every corner of life. As the design of the important carrier of commercial behavior, it also puts forward more space of study and creatation to the designers. The design of e-commerce website should not only complete business transaction, but also should enable the consumers to enjoy the convenient, comfortable, and pleasant shopping environment while making the operators get positive effect of brand awareness and image.
\end{abstract}

\section{Introduction}

E-commerce is generic terms of business activities by using advanced electronic technology. Through the network, use advanced information processing tool and computer to realize the business information, product information, sales information, service information, electronic payment and other activities with the mutually agreed trading standards. The platform carrying out electronic business is the e-commerce website, which plays an important role in the enterprise e-commerce system. Whether the website content is reasonable, the design is good, and the promotion is successful directly affects the success of e-commerce.

\section{Content of e-commerce website planning}

E-commerce website planning refers to the overall planning of the website construction and operation from strategic height. The main content should include the website construction objectives and business analysis, site targeted customer analysis, positioning analysis of website market, technical and economic feasibility analysis, choosing operational environment and tools and so on.

The website construction objectives and business analysis. Objective is the starting point of website construction. Business carried out on the internet by enterprises is based on the business requirements, product features and industry characteristics.

Analysis of site targeted customer. Investigate and analyze targeted customer, grasp the object and their needs the website may serve, plan and design the business website meeting the targeted customer group, to provide the product or service they needed, satisfy their interest and hobbies, and attract their attention, and to make the enterprise website not just stay on the level of propaganda, information releasing and simple information navigation, but truly become the business website customers needed.

Positioning analysis of website marketing. Before the production and manufacturing products, modern enterprises often make comprehensive understanding and analysis on what position their own product is in, the competitors, market share and consumer psychology. Only in this way, can the enterprises coordinate with the consumers seamless, so does the e-commerce website. Setting up a website and publishing on the internet blindly will only increase business cost, so the market positioning analysis is necessary and effective to the construction of e-commerce sites.

Feasibility analysis of technology, economy and personnel. Technical feasibility analysis mainly refers to the support analysis of hardware, software and related technology needed in the construction and operation of e-commerce website to e-commerce business process; economic feasibility analysis mainly refers to the benefit analysis of input and output of constructing and running the website; 
feasibility analysis of organization staff mainly refers to the analysis of organization design, management system, and the human resources guaranteeing the website construction and operation. Learn to manage effectively to make the security of online transaction improved. Therefore, the management system of a good e-commerce website should give full attention in this aspect.

\section{The utility principle in the design of e-commerce website}

To achieve the maximizing goal of website business functions, providing convenient and practical information service for the targeted customers is the basic principle of e-commerce website design. It includes the following aspects.

Humanized interface. Customers access to the e-commerce website to obtain the needed goods or service, so webpage content must be focused and avoid exaggeration, and the decoration should not be too much. The content arrangement must be concise to navigate; it should be split into multiple webpage when the amount of information is relatively large. In addition, the design of e-commerce webpage should also consider the need of disabled people, patients and other special populations.

Convenient and fast updating and maintenance. The e-commerce website should update the price information according to market volatility, offer new products or service, and engage in some promotional activities to stimulate customers' purchase. The design should consider the quickness and convenience of content updating. In addition, when updating the content, it should pay attention to the relative consistency in webpage structure, so that the customers can find all kinds of information needed fast and conveniently.

Ellipsis. In general, the customers can keep attention on the webpage content for about 10 seconds; if the response time of the system is more than 10 seconds, the customers will turn to other task when the computer is completing the current operation. Therefore, in order to shorten the response time of the system, a simpler solution is to minimize the use of pictures and multimedia (such as animation, video, etc) on the webpage. But as the e-commerce site, a number of occasions need to use graphical or multimedia to demonstrate, which causes to decrease the response time of the system.

Accurate link. The web is actually a huge information space. Because the space is too large and the links between nodes is perplexing, users will have a risk of "lost" phenomenon when browsing the webpage. Study of Elm and Woods in 1985 found that, the degree of users' "lost" on the internet has direct relationship with that they are not familiar with the document structure. They concluded three different forms of "lost”. First, they don't know where to go next step; second, they know where to go, but don't know how to go; three, they don't know in which location they are throughout the document structure. In order to reduce and avoid the "lost" phenomenon, two strategies can be adopted in generally: the one is to change the users' interface, such as using the technology of navigation map and multi-window display; the other is to analyze the text and change the structure and links of hypertext. Improving the quality of hypertext can effectively reduce the "lost" phenomenon of users.

Interface unity and diversity. In the design of e-commerce webpage, the consistency of the interface is an important factor needing to be considered carefully. Generally, the consistency of the interface is mainly reflected in three aspects: directivity effect, the relationship between input and output of the system, the visual effect of the interface. Some researches show that, enhancing the consistency of the interface is not only conducive to improve users' performance and satisfaction, but also can reduce the error of operation.

Beauty, scale, structure, and layout. Good visual effect is as important as strong use function. The level of interface beauty is positively correlated with users' subjective evaluation of interface usability, so is the operating performance. In 2000, Schenkman summarizes four main indexes to measure the quality of webpage appearance design: beauty, graphic scale, structure, and overall layout. Among them, the most important index is beauty.

The unification of the terminal and the carrier. The design of e-commerce webpage should adapt to various types of monitor LED used by the customers. It should use the percentage of free space to arrange composition. At present, webpage browser commonly used is Netscape and Internet Explorer, and these browsers all have the old and new versions. Sometimes, the same webpage in different 
browsers or different editions of the same browser will display different effect, even some webpage function can not achieve. As the e-commerce website, it should pay attention to the compatibility of webpage.

Information security. The internet is an open network, so all kinds of business activities on the internet will likely face the hacker's attack and viruses at any time. Therefore, ensuring the system security of information flow is very important. Safety is not only a technical problem, but also relates to the management of the system, the protection of the laws and regulations, etc.

Extensible design position. The internet has great business potential, and no one can exactly expect the ultimate access of system and the optimal mode of business operation. Therefore, one of web design principles is extendibility. Along with the expansion of business volume of online platform and the growth of platform access volume, the system should be able to have strong expansion capability to adapt to the development of new business.

\section{Problems needing to be paid attention to in the design of e-commerce design}

First, the problem of trade credit. At present, websites in the e-commerce are a lot, such as Taobao, eBay, etc. all e-commerce trading platform have their own credit system, for example, intermediary model, site model, security model, and trust model. Taking Taobao and eBay as an example, if transact through the post office or bank transfers, because the transaction is the first payment after delivery, the goods are more likely to have distinguish with the description and consumers may get more feeling of being cheated. This is one main reason causing the slow development of the e-commerce. How to better ensure that both parties are satisfied with trading becomes the focus of concern gradually. Taking eBay for example, taobao can use alipay to transact and eBay can use paypal. In the transaction, the payment is paid in pay treasure or paypal, and then paid to the sellers after receipt with satisfaction. Bank transfer and online payment is convenient and simple enough to greatly improve the credit of transaction parties and guarantee the transaction. However, if you spend 30 yuan to buy goods with 15 yuan postage and want to return due to damage or other problems, the postage is 15 yuan more and the total money can buy new goods in the local. They will have no feeling of the transaction due to no pay no goods. In fact, in addition to using pay treasure, paypal and other similar tools to improve the credit of transaction, it still needs both sides of trade to maintain calm and tolerant attitude to deal with the trade.

Second, the security of transaction. The appearance of adverse effects from SMS trap, SMS fraud, false bank, backdoor programs, hacker, Trojan injection and so on, serious affects the security of transaction. Through simple query in Taobao and eBay, you'll find that there are a lot of new goods are lower than shopping malls or online quotes, the websites releasing the information are also plausible, and most of the IP address location is Quanzhou in Fujian province. It is easy for us to think of cases of SMS fraud and internet fraud. The use of the post office remittance will have no echo sooner or later, but the emergence of false bank and hacker Trojan also makes bank transfer will be likely to end up empty handed. The objective of e-commerce website has only one, which is to make a profit. As long as completing the transaction, can it be benefit from it. Therefore, it often neglects to verify the authenticity of the seller and buyer information. Although pay treasure and bank account can improve the trade credit of both sides to a great extent and enhance the safety of transaction, the authenticity of the information and the degree of transaction satisfaction still lack scientific, standardized, and mature supervision mechanism. Therefore, economic disputes resulting will be longer.

\section{The style and creative design of the website}

The overall style and creative design of website is the one people most hope to master and the most difficult to master. The difficulty is that there is no fixed model to reference and imitate. If want to design a sit different from common website, it should study the overall style and creative design of website. The style is abstract and refers to comprehensive sense of the overall image of the site to the 
visitors; the style is unique, it is a the place different from the other sites, or color, or technology, or interactive; the style has humanity and can be summed up the personality and mood of a website according to the appearance, content, language and communication of the website. The overall style of the site design can adopt the following approach: sign the Logo on every page as much as possible; highlight your standard color; highlight your standard fonts; use clear catchy slogans; create specific symbols or icons of a site, etc. Idea is the key of the survival of a site. As a web designer, you must have good creative source. Creativity is a special way to transmit information; it is a result of thinking and recombination of the existing elements. For example, IP phone, online bookstore, online auction, electronic community, etc.

\section{Conclusions}

Compared with the traditional way of shopping, online shopping has the advantages of convenience, quickness and so on. However, virtual shopping malls and customers can transmit information through the network in the space. Therefore, e-commerce webpage must meet the requirements of people in the design, to maximize the performance of online information search and other various operations, enhance the awareness of online shopping satisfaction and sense of security, in order to create harmonious, happy, beautiful and convenient transaction space.

\section{References}

[1]Ke Xu, Tong Miao, Hui Zhao. The vision and design of webpage [M].Beijing: people’s post and telecommunication press, 2001.

[2]Suliu He. Planning and editing of network media[M]. Beijing: Beijing Broadcasting Institute press, 2001.

[3]Fanpeng Yu, Yanping Wang, Hong Shen, etc. The basic tutorial of e-commer[M].Beijing: Tsinghua University press, 2009.

[4]Xingyu Mu. Analysis and design of B2C e-commerce website[D]. Kunming: Yunnan Univeristy, 2013.

[5] Saihua Xu. Design principle of e-commerce website[J]. Science and technology innovation herald, 2009(5).

[6]Chunsheng Lu, Junfeng Zhang. Design and promotion of e-commerce website[J]. Agricultural network information, 2006(2).

[7]Yongzhen Lu, Yunlong Sun. Realizing the site management through ASP and SQL Server 2000[J]. Journal of Anshan Iron and Steel Institute, 2002(3):197-199. 